\title{
Efeitos de fertilizantes orgânicos na nutrição e produção do pimentão.
}

\author{
Simone C. Mello; Hamilton S. Pereira; Godofredo C. Vitti ${ }^{1}$ \\ ${ }^{1}$ ESALQ - Departamento de Solos e Nutrição de Plantas, C. Postal 09, 13.418-900 Piracicaba-SP. e.mail: sicmello@zaz.com.br
}

\section{RESUMO}

Avaliaram-se os efeitos de três tipos de materiais orgânicos associados com a aplicação de fertilizante mineral NPK sobre a nutrição e produção do pimentão cv. Mayata, cultivado em estufa, na região de Piracicaba (SP). O delineamento experimental foi de blocos casualizados com quatro repetições e seis tratamentos $(150 \mathrm{~g}$ cova $^{-1}$ de húmus de turfa $+100 \%$ do NPK; $150 \mathrm{~g} \mathrm{cova}^{-1}$ de húmus de turfa $+70 \%$ do NPK; $100 \mathrm{~g}$ cova $^{-1}$ de húmus de casca de pinus + $100 \%$ do NPK; $100 \mathrm{~g} \mathrm{cova}^{-1}$ de húmus de casca de pinus $+70 \%$ do NPK; 100 g cova $^{-1}$ de esterco de galinha $+100 \%$ do NPK e $100 \%$ do NPK). A dose $100 \%$ do NPK correspondeu a $100 \mathrm{~g} \mathrm{cova}^{-1}$ da fórmula 04-14-08, equivalente a $130-458-262 \mathrm{~kg} \mathrm{ha}^{-1} \mathrm{de} \mathrm{N}-\mathrm{P}_{2} \mathrm{O}_{5}-\mathrm{K}_{2} \mathrm{O}$. $\mathrm{O}$ esterco de galinha $+100 \%$ do NPK proporcionou, de modo geral, o maior peso médio de frutos e teor de fósforo nas folhas em relação à adição dos outros materiais orgânicos associados com a adubação mineral. A aplicação dos materiais orgânicos associados com fertilizante mineral NPK não aumentou o peso médio e a produção de frutos em relação à adubação NPK isolada.

Palavras-chave: Capsicum annuum, adubação orgânica, casca de pinus, esterco de galinha, pimentão.

\section{ABSTRACT}

Effects of organic manures on the nutrition and yield of pepper.

This experiment was carried out in Piracicaba, Brazil, to evaluate the effects of three types of organic materials in association with chemical fertilizers on the nutrition and yield of pepper cv. Mayata cultivated in plastic greenhouse. The experimental design consisted of randomized blocks with four replications and six treatments (150 $\mathrm{g} \mathrm{hole}^{-1}$ of peat compost plus $100 \% \mathrm{NPK} ; 150 \mathrm{~g}$ hole $^{-1}$ of peat compost plus $70 \%$ NPK; $100 \mathrm{~g} \mathrm{hole}^{-1}$ of pinus chip compost plus $100 \%$ NPK; $100 \mathrm{~g} \mathrm{hole}^{-1}$ of pinus chip compost plus $70 \% \mathrm{NPK} ; 100 \mathrm{~g} \mathrm{hole}^{-1}$ of poultry manure plus $100 \%$ NPK; $100 \%$ NPK). The NPK rate was $100 \mathrm{~g} \mathrm{cave}^{-1}$ of 04-14-08 mineral fertilizer, corresponding to 130 458-262 $\mathrm{kg} \mathrm{ha}^{-1}$ of N- $\mathrm{P}_{2} \mathrm{O}_{5}-\mathrm{K}_{2} \mathrm{O}$, respectively. The poultry manure plus $100 \%$ do NPK increased the fruits weight and leaf $\mathrm{P}$ compared to other organic materials plus $100 \%$ or $70 \%$ of NPK. The organic compost with mineral fertilization did not increase the fruits weight and yield when compared to mineral fertilization alone.

Keywords: Capsicum annuum, organic fertilization, pinus chip, poultry manure, pepper.

(Aceito para publicação em 16 de agosto de 2.000)

$\mathrm{O}$ pimentão, solanácea de alto valor alimentício, está entre as hortaliças mais consumidas no Brasil e cultivadas em ambiente protegido. A cultura respondeu, em 1990, por 1,4\% da produção nacional de hortaliças ( $9^{\circ}$ lugar), ocupando uma área de 5.470 ha, sendo que $34,23 \%$ desta concentra-se no Estado de São Paulo (Camargo Filho \& Mazzei, 1994). O cultivo desta hortaliça em estufa permite a colheita com alto rendimento e qualidade dos frutos, chegando a alcançar $40 \mathrm{t} \mathrm{ha}^{-1}$, enquanto que ao ar livre a produção média atinge $20 \mathrm{t} \mathrm{ha}^{-}$ ${ }^{1}$ (Robledo de Pedro \& Martin Vicente, 1988). Estes valores podem alcançar 80 a $150 \mathrm{t} \mathrm{ha}^{-1} \mathrm{em}^{-}$ambiente protegido e $40 \mathrm{a}$ $60 \mathrm{t} \mathrm{ha}^{-1}$ ao ar livre (Serrano Cermëno, 1990).

O cultivo de hortaliças, caracterizado pelo uso intensivo de insumos e mãode-obra, está sujeito às variações estacionais de oferta e preço dos produtos no mercado. Assim, tornam-se necessários o planejamento adequado da produção e a utilização de tecnologia apurada por parte do olericultor (Faria
Junior, 1997). Como consequência, o conhecimento de práticas agrícolas como a adubação e seu efeito na nutrição mineral e na produção do pimentão são necessários para que os produtores utilizem de forma racional e econômica os fertilizantes. No Brasil, em condições de cultivo protegido, as publicações sobre adubação na cultura do pimentão são escassos, principalmente aqueles relacionados ao uso de fertilizantes orgânicos.

A matéria orgânica é um dos insumos mais empregados em termos de volume na produção de hortaliças, utilizando-se, comumente, doses superiores a $20 \mathrm{tha}^{-1}$, dependendo das características e custo do produto. Por outro lado, não está claro que os materiais orgânicos podem substituir parte da adubação mineral na cultura do pimentão (Roe et al., 1997). Em experimentos conduzidos por estes autores, na Flórida, observou-se comportamento diferenciado de compostos orgânicos associados ou não a fertilizante mineral NPK na produção de frutos. Estes autores concluíram ainda que a adição de $134 \mathrm{t}^{-} \mathrm{a}^{-}$
${ }^{1}$ de composto orgânico (cavaco de madeira com restos de curral) associado com $50 \%$ da taxa de fertilizante mineral (71-39-44 $\mathrm{kg} \mathrm{ha}^{-1}$ de N-P-K no plantio e $283-0-278 \mathrm{~kg} \mathrm{ha}^{-1}$ de N-P-K em cobertura) reduziu a produção comercial de frutos; Por outro lado, a adição de composto, derivado de resíduo de papel misturado com restos de biossólidos de curral, com $100 \%$ da taxa de fertilizante mineral, aumentou a produção total de frutos em relação à adubação mineral. Hartz et al. (1996) observaram benefício da adição de $17 \mathrm{ou}$ $34 \mathrm{t} \mathrm{ha}^{-1}$ de composto orgânico, derivado de resíduos vegetais de origem urbana, sobre a produção de frutos de pimentão quando associado a baixa dose de fertilizante nitrogenado $\left(168 \mathrm{~kg} \mathrm{ha}^{-1} \mathrm{de}\right.$ N). Entretanto, os efeitos positivos desta associação não foram observados quando se empregou $280 \mathrm{~kg} \mathrm{ha}^{-1} \mathrm{de} \mathrm{N}$.

Realizou-se este trabalho com o objetivo de avaliar os efeitos da adição de húmus de turfa, húmus de casca de pinus e esterco de galinha associados ou não com fertilizante mineral NPK na nutri- 
Tabela 1. Características químicas dos fertilizantes orgânicos utilizados, com base no peso seco. Piracicaba, ESALQ, 1995/96.

\begin{tabular}{|c|c|c|c|}
\hline \multirow[t]{2}{*}{ Características avaliadas } & $\begin{array}{c}\text { Húmus de } \\
\text { turfa }\end{array}$ & $\begin{array}{l}\text { Húmus de } \\
\text { pinus }\end{array}$ & $\begin{array}{c}\text { Esterco de } \\
\text { galinha }\end{array}$ \\
\hline & \multicolumn{3}{|c|}{ Conc. na mat. seca } \\
\hline $\mathrm{pH}$ em CaCl2 0,01 M & 7,2 & 6,9 & 6,0 \\
\hline Matéria org. total (g kg-1) & 255,3 & 266,2 & 590,0 \\
\hline$C$ total $(\mathrm{g} \mathrm{kg}-1) 1$ & 141,8 & 147,9 & 330,0 \\
\hline $\mathrm{N}$ total $(\mathrm{g} \mathrm{kg}-1) 2$ & 9,2 & 12,0 & 36,0 \\
\hline$P$ total $(g \mathrm{~kg}-1) 3$ & 1,1 & 3,2 & 6,7 \\
\hline K total $(\mathrm{g} \mathrm{kg}-1) 4$ & 2,9 & 13,9 & 21,9 \\
\hline Ca total (g kg-1) 4 & 15,0 & 17,0 & 19,9 \\
\hline Mg total (g kg-1) 4 & 1,0 & 3,6 & 5,2 \\
\hline$S$ total $(\mathrm{g} \mathrm{kg}-1) 5$ & 0,6 & 4,5 & 5,5 \\
\hline Relação C/N & $15 / 1$ & $12 / 1$ & $9 / 1$ \\
\hline
\end{tabular}

ção mineral e produção do pimentão cultivado em estufa.

\section{MATERIAL E MÉTODOS}

O experimento foi realizado no município de Piracicaba-SP, no período de agosto de 1995 a março de 1996 em solo Podzólico Vermelho-Amarelo abrupto, eutrófico, A moderado, textura arenosa/ média, cujas características químicas foram: $\mathrm{pH}\left(\mathrm{CaCl}_{2}\right)$ 4,3; M.O. $\left(\mathrm{mg} \mathrm{dm}^{-3}\right)$ 17; $\mathrm{P}\left(\mathrm{mg} \mathrm{dm}^{-3}\right)$ 10; $\mathrm{K}\left(\mathrm{mmol}_{\mathrm{c}} \mathrm{dm}^{-3}\right) 2,8 ; \mathrm{Ca}$ $\left(\mathrm{mmol}_{\mathrm{c}} \mathrm{dm}^{-3}\right)$ 28; $\mathrm{Mg}\left(\mathrm{mmol}_{\mathrm{c}} \mathrm{dm}^{-3}\right)$ 9; $\mathrm{H}+\mathrm{Al}\left(\mathrm{mmol}_{\mathrm{c}} \mathrm{dm}^{-3}\right) 34 ; \mathrm{B}\left(\mathrm{mg} \mathrm{dm}^{-3}\right)$ 0,7; $\mathrm{Cu}\left(\mathrm{mg} \mathrm{dm}^{-3}\right)$ 1,14; Fe $\left(\mathrm{mg} \mathrm{dm}^{-3}\right)$ 68; $\mathrm{Mn}$ (mg dm$\left.{ }^{-3}\right)$ 156,4; $\mathrm{Zn}\left(\mathrm{mg} \mathrm{dm}^{-3}\right)$ 1,8.

Sessenta dias após o preparo do solo (uma aração e uma gradagem) e incorporação de $2 \mathrm{t} \mathrm{ha}^{-1}$ de calcário calcítico, (enxada rotativa), para elevar a saturação por bases a 70\%, (Passos, 1985), realizou-se a adubação de plantio em área total da parcela. Nesta adubação foram aplicadas $50 \mathrm{~g} \mathrm{cova}^{-1}$ de húmus de turfa ou $100 \mathrm{~g} \mathrm{cova}^{-1}$ de húmus de pinus associados com 70 ou $100 \%$ do NPK, 100 $\mathrm{g} \mathrm{cova}^{-1}$ de esterco de galinha mais $100 \%$ do NPK e $100 \%$ do NPK isoladamente. O NPK correspondeu a $100 \mathrm{~g} \mathrm{cova}^{-1} \mathrm{de}$ 04-14-08 equivalente a 130-458-262 de $\mathrm{N}-\mathrm{P}_{2} \mathrm{O}_{5}-\mathrm{K}_{2} \mathrm{O}$. Foram feitas duas adubações de cobertura, aos 20 e 40 dias após o transplante, aplicando-se manualmente $50 \mathrm{~g} \mathrm{cova}^{-1}$ de sulfato de amônio nos tratamentos com $70 \%$ do NPK e 30 g cova $^{-1}$ nos tratamentos com $100 \%$ do NPK. Nas parcelas referentes aos húmus de turfa também efetuaram-se duas coberturas com $50 \mathrm{~g} \mathrm{cova}^{-1}$ desse material orgânico.

O húmus de turfa foi obtido em turfeiras naturais da região de Capão Bonito. O húmus de pinus foi obtido, de fábricas de celulose que usam o pínus como matéria-prima, por meio da humificação em pátios a céu aberto do material descartado (casca) durante o processo de industrialização. $\mathrm{O}$ esterco de galinha foi obtido raspando-se o chão de granjas de galinhas poedeiras. As características químicas dos fertilizantes orgânicos constam da Tabela 1.

A cultivar utilizada foi a Mayata por ser bastante plantada em ambiente protegido. As mudas foram produzidas em bandejas de 128 células, empregandose como substrato o Plantimax, e transplantadas aos 25 dias após a germinação (19/08/95), quando apresentavam a terceira folha formada. O plantio foi feito em estufa plástica, de estrutura metálica na forma de arco com $7 \mathrm{~m}$ de largura por 60 metros de comprimento e altura do vão central de $4,5 \mathrm{~m}$, com as laterais fechadas com tela de sombrite preto com $30 \%$ de sombra.

$\mathrm{O}$ delineamento experimental foi o de blocos ao acaso com seis tratamentos (descritos anteriormente), e quatro repetições, totalizando 24 parcelas. As doses dos fertilizantes orgânicos foram feitas com base no teor de N (Tabela 1). Cada parcela experimental foi composta de duas linhas com 16 plantas por linha, totalizando uma área útil de $9,5 \mathrm{~m}^{2}$. A densidade de plantas foi de 32.653 plantas ha ${ }^{-1}$.

No período do aparecimento do primeiro fruto maduro realizou-se a amostragem de folhas, coletando-se a primeira folha logo abaixo da segunda flor aberta, num total de 10 folhas por parcela, de acordo com Malavolta et al. (1989). As folhas foram lavadas e secadas em estufa com temperatura média de $70^{\circ} \mathrm{C}$ por 48 horas e posteriormente moídas para a avaliação dos teores de macronutrientes, de $\mathrm{B}, \mathrm{Cu}, \mathrm{Fe}$, Mn e Zn (Malavolta et al., 1989).

Tratos culturais, como capinas, desbrotas e irrigação por gotejamento, foram feitos periodicamente de acordo com as necessidades da cultura. Durante o período vegetativo e a fase de préfloração as pulverizações contra pragas e doenças foram feitas preventivamente. Realizaram-se, também, aplicações foliares de ácido bórico $(0,07 \%)$ e Profol Mn $(0,05 \%)$, quinzenalmente até o final da colheita. As colheitas foram realizadas manualmente para as avaliações da produção e peso médio de frutos por parcela. A colheita abrangeu o período de 16/10/1995 a 08/03/1996, sendo que a maior parte dos frutos foi colhida ainda verde.

\section{RESULTADOS E DISCUSSÃO}

Para o peso médio de frutos e para a produção total, os tratamentos referentes à adição dos materiais orgânicos associados com 70 ou $100 \%$ da adubação mineral NPK não diferiram significativamente da adubação mineral NPK (Tabela 2). Este fato também foi constatado por Roe et al. (1997), os quais não observaram aumento na produção comercial de frutos de pimentão com a aplicação de $134 \mathrm{t} \mathrm{ha}^{-1}$ de composto orgânico e $100 \%$ do nível de aplicação de fertilizante NPK (71-39-44 $\mathrm{kg} \mathrm{ha}^{-1}$ de N-P-K no plantio e $283-278 \mathrm{~kg} \mathrm{ha}^{-1}$ de N-K em cobertura) em relação ao fertilizante mineral somente. Segundo estes autores, a adição de fertilizante mineral pode mascarar os efeitos benéficos da adição do material orgânico sobre a pro- 
dução de pimentão. Esta afirmação foi comprovada por Hartz et al. (1996), onde a aplicação de 17 ou $34 \mathrm{t} \mathrm{ha}^{-1}$ de composto, derivado de resíduos vegetais, não afetou a produção de frutos de pimentão quando associada com $280 \mathrm{~kg}$ $\mathrm{ha}^{-1}$ de $\mathrm{N}$ como fertilizante mineral.

Por outro lado, a adição de esterco de galinha com $100 \%$ do nível de fertilizante NPK proporcionou maior peso médio de frutos em relação ao húmus de turfa com 70 ou $100 \%$ da adubação NPK e ao húmus de pinus com 100\% do fertilizante NPK (Tabela 2). Levando-se em consideração as características dos materiais orgânicos (Tabela 1), observa-se que o húmus de turfa e de pinus apresentam baixo conteúdo de matéria orgânica e teores de nutrientes inferiores ao esterco de galinha. Além disso, a menor relação $\mathrm{C} / \mathrm{N}$ desse material proporcionou, provavelmente, maior taxa de mineralização e consequentemente maior disponibilidade de nitrogênio e de outros elementos para as plantas. Portanto, a maior concentração de nutrientes por $\mathrm{kg}$ de esterco de galinha pode explicar estes resultados obtidos. Para a produção total, a adição de esterco de galinha mais $100 \%$ do NPK proporcionou $36 \%$ de aumento em comparação ao tratamento húmus de pinus mais $70 \%$ do NPK. Dentro do mesmo tipo de adubo orgânico, seja para o húmus de turfa ou para o húmus de pinus, a redução de $30 \%$ do fertilizante mineral NPK não alterou o peso médio de frutos e a produção total do pimentão, o que permite inferir que 70 $\mathrm{g} \mathrm{cova}^{-1}$ de 4-14-08 foi suficiente para a obtenção de uma boa produtividade.

Os teores de macro e micronutrientes nas folhas de pimentão estão apresentados na Tabela 3. O teor de $\mathrm{P}$ na folha foi maior com a adição de esterco de galinha mais $100 \%$ de NPK em relação aos outros tratamentos, com exceção do húmus de turfa mais $100 \%$ de NPK. Por meio das concentrações de fósforo nos materiais orgânicos (Tabela 1 ), verifica-se que o teor desse elemento no esterco de galinha, foi em torno de seis a duas vezes superior ao húmus de turfa e ao húmus de pinus, respecti- vamente. Este fato e, possivelmente, a presença do $\mathrm{P}$, na sua maior parte, na forma inorgânica no esterco de galinha, podem explicar o aumento na concentração foliar de $\mathrm{P}$ com a adição desse material orgânico. Em comparação à adubação mineral, a aplicação do esterco de galinha mais $100 \%$ NPK aumentou em $27 \%$ o teor de $\mathrm{P}$ nas folhas. Incrementos no conteúdo de $\mathrm{P}$ no tecido foliar de plantas de pimentão também foram obtidos com a adição de 50 a 250 $\mathrm{m}^{3} \mathrm{ha}^{-1}$ de esterco de suíno (Bernal \& Roig, 1993).

A concentração de cálcio nas folhas foi superior para o húmus de pinus mais $100 \%$ de NPK e para o esterco de galinha mais $100 \%$ de NPK em relação aos

Tabela 2. Peso médio e produção total dos frutos de pimentão cv. Mayata. Piracicaba, ESALQ, 1995/96.

\begin{tabular}{lcc}
\hline \multicolumn{1}{c}{ Tratamentos } & $\begin{array}{c}\text { Peso médio de } \\
\text { frutos (g/fruto) }\end{array}$ & Produção (t/ha) \\
\hline Húmus de turfa + $100 \%$ NPK & $123,24 \mathrm{~b}$ & $85,8 \mathrm{ab}$ \\
Húmus de turfa + $70 \%$ NPK & $123,50 \mathrm{~b}$ & $91,1 \mathrm{ab}$ \\
Húmus de pinus + $100 \%$ NPK & $123,75 \mathrm{~b}$ & $85,3 \mathrm{ab}$ \\
Húmus de pinus + 70\% NPK & $128,50 \mathrm{ab}$ & $70,3 \mathrm{~b}$ \\
Esterco de galinha + $100 \%$ NPK & $148,00 \mathrm{a}$ & $95,6 \mathrm{a}$ \\
$100 \%$ NPK & $136,50 \mathrm{ab}$ & $83,3 \mathrm{ab}$ \\
\hline C.V. (\%) & 7,37 & 9,7 \\
\hline D.M.S. (5\%) & 22,13 & 17,6 \\
\hline
\end{tabular}

*/ Médias seguidas de mesma letra nas colunas não diferem entre si a 5\% de probabilidade pelo teste de Tukey.

Tabela 3. Teores foliares de nutrientes em plantas de pimentão cv. Mayata. Piracicaba, ESALQ, 1995/96.

\begin{tabular}{|c|c|c|c|c|c|c|c|c|c|c|c|}
\hline \multirow{2}{*}{ Tratamentos } & $\mathbf{N}$ & $\mathbf{P}$ & K & $\mathrm{Ca}$ & Mg & $\mathbf{S}$ & B & $\mathrm{Cu}$ & $\mathrm{Fe}$ & Mn & Zn \\
\hline & \multicolumn{6}{|c|}{$\mathrm{g} \mathrm{kg}^{-1}$} & \multicolumn{5}{|c|}{$\mathrm{mg} \mathrm{kg}^{-1}$} \\
\hline $\begin{array}{l}\text { Húmus de turfa }+ \\
100 \% \text { NPK }\end{array}$ & 42,2 n.s. & $2,5 a b$ & 45,8 n.s. & $9,1 \mathrm{~b}$ & 3,3 n.s. & 4,4 n.s. & 277 n.s. & 16 n.s. & 61 n.s. & 272 n.s. & 40 n.s. \\
\hline $\begin{array}{l}\text { Húmus de turfa }+ \\
70 \% \text { NPK }\end{array}$ & 39,7 & $2,3 \quad b$ & 44,9 & $8,9 \mathrm{~b}$ & 2,7 & 4,3 & 270 & 15 & 59 & 302 & 38 \\
\hline $\begin{array}{l}\text { Húmus de pinus } \\
+100 \% \mathrm{NPK}\end{array}$ & 41,7 & $2,4 \quad b$ & 46,1 & $11,2 \mathrm{a}$ & 3,2 & 4,5 & 266 & 13 & 67 & 328 & 39 \\
\hline $\begin{array}{l}\text { Húmus de pinus } \\
+70 \% \text { NPK }\end{array}$ & 42,4 & $2,4 \quad b$ & 45,0 & $10,6 a b$ & 3,1 & 4,4 & 265 & 12 & 68 & 349 & 35 \\
\hline $\begin{array}{l}\text { Esterco de galinha } \\
+100 \% \text { NPK }\end{array}$ & 40,8 & $2,8 \mathrm{a}$ & 45,5 & $11,1 \mathrm{a}$ & 3,2 & 4,4 & 254 & 12 & 66 & 305 & 34 \\
\hline $100 \%$ NPK & 40,5 & $2,2 b$ & 44,2 & $9,5 a b$ & 2,9 & 4,3 & 268 & 14 & 64 & 339 & 39 \\
\hline C.V. (\%) & 4,1 & 7,1 & 4,5 & 7,3 & 17,2 & 5,7 & 18 & 15 & 6 & 16 & 10 \\
\hline D.M.S. (5\%) & 3,8 & 0,4 & 4,6 & 1,7 & 1,2 & 0,6 & 110,0 & 4,9 & 9,4 & 114,1 & 8,8 \\
\hline
\end{tabular}

Médias seguidas de mesma letra nas colunas não diferem entre si a $5 \%$ de probabilidade pelo teste de Tukey. 
tratamentos húmus de turfa associado com 70 ou $100 \%$ da adubação NPK, provavelmente em virtude dos teores de $\mathrm{Ca}^{++}$mais elevados no esterco de galinha e no húmus de pinus (Tabela 1), que tornaram-se posteriormente disponíveis para as plantas.

As concentrações dos demais nutrientes nas folhas não foram afetadas pelos tratamentos empregados (Tabela 3). Sabese que a matéria orgânica pode alterar a composição mineral das plantas; entretanto, este efeito depende dentre outros fatores, da fertilidade do solo (Warman, 1990), das características do material orgânico e da sua quantidade aplicada (Asiegbu \& Oikeh, 1995). Dessa forma, as pequenas quantidades aplicadas dos materiais orgânicos, ou seja, 3,3 tha ${ }^{-1}$ de esterco de galinha, $4,9 \mathrm{t} \mathrm{ha}^{-1}$ de húmus de turfa e $3,3 \mathrm{tha}^{-1}$ de húmus de pinus, e os teores dos nutrientes no solo, considerados altos, com exceção do $\mathrm{P}$ e do $\mathrm{K}$, podem ter contribuído para a ausência de alterações nas concentrações foliares de $\mathrm{N}, \mathrm{K}, \mathrm{Mg}, \mathrm{S}, \mathrm{B}, \mathrm{Cu}$, $\mathrm{Fe}, \mathrm{Mn}$ e $\mathrm{Zn}$.

Com exceção do B e do Mn, os teores foliares dos outros nutrientes (Tabela 3) encontram-se dentro das faixas consideradas adequadas para estes elementos nas folhas de pimentão, segundo Trani \& Raij (1996). Os teores foliares de B e de Mn, por sua vez, foram superiores aos limites máximos descritos por estes autores, provavelmente em virtude das pulverizações foliares realizadas quinzenalmente com esses dois micronutrientes. Entretanto, os valores encontrados para o B e o Mn não foram prejudiciais ao desenvolvimento da cultura.

Tornou-se claro, portanto, a influência do tipo de material orgânico na nutrição e produtividade do pimentão cv. Mayata, evidenciando a necessidade de outros estudos envolvendo diferentes materiais orgânicos, como fonte de nutrientes, com o objetivo de se reduzir a adubação mineral.

\section{LITERATURA CITADA}

ASIEGBU, J.E.; OIKEH, S. Evaluation of chemical composition of manures from different organic wastes and their potential for supply of nutrients to tomato in a tropical Ultisol. Biological Agriculture Horticulture, v. 12, p. 47-60, 1995.

BERNAL, M.P.; ROIG, A. The influence of pig slurry fertilization on the mineral content of horticultural crops grown in calcareous soils. Journal Science Food Agricultural, v. 62, p. 129-135, 1993.

CAMARGO FILHO, W.P.; MAZZEI, A.R. Hortaliças prioritárias no planejamento da produção orientada: estacionalidade da produção e dos preços. Informe Econômico, v. 24, p. 954, 1994.
FARIA JUNIOR, M.J.A. Avaliação de diferentes arquiteturas de estufas, coberturas do solo com filme plástico, em híbridos de pimentão (Capsicum annuum L.). Jaboticabal: UNESP, 1997. 102 p. (Tese doutorado).

HARTZ, T.K.; COSTA, F.J.; SCHADER, R.W.L. Suitability of composted green waste for horticultural uses. HortScience, v. 31, p. 961964, 1996.

MALAVOLTA, E.; VITTI, G.C.; OLIVEIRA, S.A. Avaliação do estado nutricional das plantas, princípios e aplicações. Piracicaba: POTAFOS, 1989. 201 p.

PASSOS, F.A. In: INSTITUTO AGRONÔMICO DE CAMPINAS. Recomendações de adubação e calagem para o Estado de São Paulo. Campinas, 1985. p. 63. (IAC. Boletim Técnico, 100).

ROBLEDO DE PEDRO, F.; MARTIN VICENTE, L. Applicación de los plásticos en la agricultura. Madri: Mundi-Prensa, 1988. 573 p.

ROE, N.E.; STOFFELLA, P.J.; GRAETZ, D. Composts from various municipal solid waste feedstocks affect vegetable crops. II. Growth, yields, and fruit quality. Journal American Society Horticultural Science, v. 122, p. 433437, 1997.

SERRANO CERMËNO, Z. Estufas: instalação e maneio. Lisboa, Litexa, 1990. 355 p.

TRANI, P.E.; RAIJ, B. van. Hortaliças. In: INSTITUTO AGRONÔMICO DE CAMPINAS. Recomendações de adubação e calagem para o Estado de São Paulo. Campinas, 1996. p. 155-203. (IAC. Boletim Técnico, 100).

WARMAN, P.R. Fertilization with manures and legume intercrops and their influence on Brassica and tomato growth, and on tissue and soil copper, manganese and zinc. Biological Agriculture Horticulture, v. 6, p. 325-335, 1990. 